\title{
Green Synthesis of Robust, Biocompatible Silver Nanoparticles Using Garlic Extract
}

\section{Gregory Von White II, ${ }^{1}$ Petra Kerscher, ${ }^{1}$ Ryan M. Brown, ${ }^{1}$ Jacob D. Morella, ${ }^{1}$ William McAllister, ${ }^{2}$ Delphine Dean, ${ }^{2}$ and Christopher L. Kitchens ${ }^{1}$}

\author{
${ }^{1}$ Department of Chemical and Biomolecular Engineering, Clemson University, Clemson, SC 29634, USA \\ ${ }^{2}$ Department of Bioengineering, Clemson University, Clemson, SC 29634, USA
}

Correspondence should be addressed to Christopher L. Kitchens, ckitche@clemson.edu

Received 22 January 2012; Accepted 16 February 2012

Academic Editor: Chunyi Zhi

Copyright (C) 2012 Gregory Von White II et al. This is an open access article distributed under the Creative Commons Attribution License, which permits unrestricted use, distribution, and reproduction in any medium, provided the original work is properly cited.

\begin{abstract}
This paper details a facile approach for the synthesis of stable and monodisperse silver nanoparticles performed at ambient/low temperature, where Allium sativum (garlic) extract functions as the silver salt reducing agent during nanoparticle synthesis as well as the postsynthesis stabilizing ligands. Varying the synthesis conditions provides control of particle size, size-distribution, and kinetics of particle formation. Infrared spectroscopy, energy dispersive X-ray chemical analysis, and high-performance liquid chromatography indicated that allicin and other carbohydrates in the garlic extract are the primary nanoparticle stabilizing moieties. The synthesized silver nanoparticles also demonstrate potential for biomedical applications, owing to (1) enhanced stability in biological media, (2) resistance to oxidation by the addition of $\mathrm{H}_{2} \mathrm{O}_{2}$, (3) ease and scalability of synthesis, and (4) lack of harsh chemicals required for synthesis. Cytotoxicity assays indicated no decrease in cellular proliferation for vascular smooth muscle cells and 3T3 fibroblasts at a concentration of $25 \mu \mathrm{g} / \mathrm{mL}$, confirming that silver nanoparticles synthesized with garlic extract are potential candidates for future experimentation and implementation in the biomedical field.
\end{abstract}

\section{Introduction}

Metallic nanoparticles have been extensively investigated due to their unique size-dependent properties [1-4] which make them useful in a variety of applications including optical/chemical sensors, [5, 6] electronic devices, [7], and catalysts [8]. Widespread synthesis protocols used for nanoparticle production often require the use of harsh organic solvents/surfactants [9-11] and strong reducing agents (e.g., borohydride or hydrazine) [12-15], which typically generate large quantities of hazardous waste. Hence, nanoparticle synthesis procedures that eliminate the use of hazardous reagents $[9,16-18]$ and afford greener, more cost-effective alternatives are becoming more desirable as the number of nanoparticle applications increases.

This is particularly true for biomedical research applications of metallic nanoparticles, which are rapidly growing due to their potential as therapeutic $[19,20]$ and contrasting agents [21]. To this end, numerous researchers have presented cell cytotoxicity studies as well as evaluations of nanoparticle stability in biological media. It has been well demonstrated that biological media necessary for cellular growth and proliferation-solutions of glucose, aminoacids, salts, vitamins, and so forth, (chemically similar to in vivo conditions) - cause irreversible nanoparticle agglomeration. For example, Greulich et al. found that silver nanoparticles stabilized by polyvinyl pyrrolidone (PVP) aggregate once exposed to biological media; however, nanoparticle conjugation with fetal calf serum improved stability [22]. In addition, Liu and Hurt showed that increasing the concentration of capping agent (citrate) in solution and/or altering the $\mathrm{pH}$ of the aqueous dispersions of silver nanoparticles reduced aggregation and led to a decrease in $\mathrm{Ag}^{+}$release in biological media [23]. Exposure to reactive oxygen species (ROS, for example, $\mathrm{H}_{2} \mathrm{O}_{2},{ }^{\bullet} \mathrm{OH}$, and $\mathrm{O}_{2}{ }^{--}$) can inhibit or render the intended nanoparticle application useless as a result of oxidization followed by irreversible agglomeration. Living cells exposed to toxins and/or nanoparticles can produce 
ROS as a response to stress and may lead to cell death [24-26]. Hence, methods to provide stable nanoparticle dispersions that resist aggregation in biological media and have high oxidation resistance are of significant importance. It is also desirable to employ natural and renewable reagents during synthesis because (1) higher potential for biocompatibility exists, which may eliminate the need for extensive postsynthesis purification or surface modification as compared to conventional synthesis procedures that use known cytotoxic compounds $[18,27]$ and (2) the methods provide a cost-effective and facile nanoparticle production process with potential for commercial scale.

A common approach for green nanoparticle synthesis at ambient temperature is to begin with naturally available resources containing phytochemicals that function as both the reducing and stabilizing agents (following green Chemistry Principles 3-5, 7, and 12-less Hazardous chemical syntheses, designing safer chemicals, safer solvents and auxiliaries, using renewable feedstocks, and inherently safer chemistry for accident prevention, resp.) [28, 29]. For example, $\sim 15 \mathrm{~nm}$-diameter gold nanoparticles have been synthesized in aqueous media by Philip et al. using honey [30]. Shukla et al. used soybean extracts to produce nontoxic gold nanoparticles and suggested that they are ideal for use in nanomedicine as a result of their stability in various biological media and in vitro compatibility [31]. Other studies of silver and gold nanoparticle synthesis have employed herbal extracts from alfalfa [32], lemongrass [33], and green tea [34], where the natural extracts serve as both reducing and stabilizing agents.

Here, we demonstrate a facile one-pot "green" synthesis of monodisperse silver nanoparticles (4 to $6 \mathrm{~nm}$ ) which utilizes Allium sativum (garlic) extract as the reducing and stabilizing agents. Varying the synthesis conditions (garlic extract concentration and temperature) enables control over nanoparticle size and size-distribution of the final dispersions. We demonstrate that garlic extract-stabilized silver nanoparticles are resistant to aggregation in the presence of biological media and have high oxidative resistance in the presence of hydrogen peroxide $\left(\mathrm{H}_{2} \mathrm{O}_{2}\right)$ compared to commonly prepared citrate-stabilized nanoparticles. Moreover, cytotoxicity assays performed on 3T3 fibroblasts and rat aortic vascular smooth muscle cells (VSMCs) demonstrated no decrease in cellular proliferation, indicating the enhanced biocompatibility of the garlic extract prepared nanoparticles. As a result of the abundant and desirable medicinal characteristics of garlic [35-38], these nanoparticles may be applicable in biomedical therapies, diagnosis, and sensing or aid in the development of novel technologies with significant attention to nanoparticle health and safety.

\section{Experimental}

2.1. Materials. Silver nitrate $\left(\mathrm{AgNO}_{3}, 99.995 \%\right)$ was purchased from VWR. The stabilizing agent sodium citrate dihydrate $(99 \%)$, reducing agent sodium borohydride $\left(\mathrm{NaBH}_{4}\right.$, $98 \%), 1 \mathrm{~N}$ nitric acid $\left(\mathrm{HNO}_{3}\right)$, and the sugars fructose and sucrose were purchased from VWR. Hydrogen peroxide $\left(\mathrm{H}_{2} \mathrm{O}_{2}, 30 \%\right)$ was obtained from Thermo Fischer. Sterile and filtered $(0.1 \mu \mathrm{m})$ Hyclone DMEM/high modified media (4.0 mM L-glutamine, $4.5 \mathrm{mg} / \mathrm{L}$ glucose, without sodium pyruvate and phenol red) and minimum essential media (MEM, without phenol red) were obtained from Thermo Scientific. Garlic was purchased from a local grocery store (Ingles in Central, SC, USA), peeled, and then rinsed with deionized water before use. All glassware was washed and rinsed with deionized water, followed by subsequent drying.

Dulbecco's modified Eagle's medium (DMEM) and PBS buffer solution employed for cell isolation and culture were purchased from Fisher Scientific. The fetal bovine serum (FBS), 1\% antibiotic-antimycotic solution, and ethyldiaminetetaacetic acid were acquired from Sigma. CytoTox 96 nonradioactive cytotoxicity assay was purchased from Promega.

\subsection{Characterization}

2.2.1. Transmission Electron Microscopy (TEM) and Energy Dispersive X-Ray (EDX). All TEM images were obtained using a Hitachi 7600 with an accelerating voltage of $120 \mathrm{kV}$. TEM and EDX samples were prepared by drop casting $\sim 5 \mu \mathrm{L}$ of nanoparticle dispersion onto a formvar carbon-coated copper TEM grid (Ted Pella), followed by air drying at ambient conditions. TEM samples were stored in a desiccator and imaged shortly after collection. The size distributions were determined by image analysis using the ImageJ software package [39]. At least 200 nanoparticles were counted for meaningful and relevant statistics. All EDX analysis was performed on a Hitachi 4800 (scanning electron microscope, SEM) in TEM mode with an accelerating voltage of $30 \mathrm{kV}$.

\subsubsection{Ultraviolet-Visible (UV-VIS) Absorbance Spectroscopy.} UV-VIS analysis was performed on a Varian Cary 50 spectrophotometer. Deionized water was used for background correction of all UV-VIS spectra. All samples were loaded into a $1 \mathrm{~cm}$ path length quartz cuvette for sampling. UVVIS spectra were fit with Gaussian curves correcting for a cubic background in Igor Pro 6.1 (Wavemetrics, Portland, OR, USA) for full-width at half maximum (FWHM) and wavelength of maximum absorbance measurements. The Gaussian fits to the UV-VIS spectra all had goodness of fit values $\left(\chi^{2} \sim 1\right)$, indicating accurate curve analysis.

\subsubsection{Attenuated Total Reflectance Fourier Transform-Infrared} (ATR-FTIR) Spectroscopy. ATR-FTIR spectroscopy was performed on a Thermo-Fisher instrument using a ThermoNicolet Magna 550 FTIR spectrometer equipped with a Thermo-SpectraTech Foundation Series Diamond ATR accessory. Here, 16 sample scans were taken (at room temperature), and the resolution for the sample and background was $4 \mathrm{~cm}^{-1}$. All purified nanoparticle dispersions and garlic extracts were dried in a vacuum oven set to $40^{\circ} \mathrm{C}$ to form powders. The dried samples were then placed on the spectrophotometer for analysis. 
2.2.4. Zeta-Potential. Zeta-potential measurements were performed on a Malvern Zetasizer Nano-ZS (ZEN3600) at $25^{\circ} \mathrm{C}$ with an incident wavelength of $633 \mathrm{~nm}$ and a $173^{\circ}$ backscattering angle. Clear disposable zeta-potential cells ( $1 \mathrm{~cm}$ path length) were rinsed with ethanol, followed by deionized water prior to sample loading. The viscosity, refractive index, and absorption values were provided in the Malvern software for water $(\mu=0.8872 \mathrm{cP}, \mathrm{RI}=0.135)$ and crystalline silver $(\mathrm{RI}=1.3330$, absorption $=3.987)$. Twelve runs were averaged for each liquid sample for accurate determination of zeta-potential measurements.

2.2.5. High Performance Liquid Chromatography (HPLC). HPLC was performed using a Waters 1525 Binary HPLC Pump in conjunction with a Waters 2414 RI detector and a Waters 2998 PDA Detector (UV detection at $254 \mathrm{~nm}$ ). A symmetry Waters C18 column with $3.5 \mu \mathrm{m}$ pore size $($ dimensions $=4.6 \times 75 \mathrm{~mm}$, total column volume $=0.75 \mathrm{~mL}$ ) was employed for garlic extract analysis. All injections were made at $25^{\circ} \mathrm{C}$, where the mobile phase was $50 / 50 \mathrm{v} / \mathrm{v}$ water/methanol and were $50 \mu \mathrm{L}$ in volume.

2.3. Garlic Extract Preparation. Approximately $6 \mathrm{~g}$ of garlic was chopped (not crushed) into $\sim 1 / 4^{\prime \prime}$ pieces, added to $50 \mathrm{~mL}$ of deionized water, and allowed to sit at room temperature for 24 hours. The resulting solution was decanted to collect a pale white transparent garlic extract solution, and the solid garlic pieces were removed. The garlic extract concentration was determined to be $22.9 \pm$ $0.5 \mathrm{mg} / \mathrm{mL}$ by measuring the remaining solid weight after evaporating $2.0 \mathrm{~mL}$ of liquid extract in a vacuum oven at $40^{\circ} \mathrm{C}$, averaging three measurements. Crushing the garlic prior to soaking and/or soaking at elevated temperatures was found to increase the extraction efficiency resulting in larger mass concentrations of extract. The variation in garlic extract preparation directly impacts the nanoparticle synthesis, that is, larger quantities of garlic extract employed during synthesis were found to generate polydisperse populations of nanoparticles. It is also likely that the extract composition is significantly dependent on the extraction methods, for example, chopping versus crushing and temperature of the extraction.

2.4. Silver Nanoparticle Synthesis. Varying quantities of garlic extract solution $(1.0 \mathrm{~mL}$ to $2.5 \mathrm{~mL})$ were added to $51 \mathrm{~mL}$ of $0.98 \mathrm{mM}$ of $\mathrm{AgNO}_{3}$ in DI water. Within two hr, a light orange color change was observed, indicating the presence of silver nanoparticles. The solution was allowed to age for $48 \mathrm{hr}$ to yield a deep orange/brown color. The silver nanoparticle dispersions were centrifuged for $15 \mathrm{~min}$ at $8,000 \mathrm{rpm}$ to remove any large aggregates and excess free garlic extract from the solution. The yellow/orange supernatant was collected and kept as the final silver nanoparticle product. The precipitate containing excess garlic extracts (the higher molecular weight components, likely fructan) and nanoparticle aggregates were discarded appropriately. A water bath maintained at $60^{\circ} \mathrm{C}$ was used in experiments investigating the effect of temperature on nanoparticle synthesis. Accelerated synthesis was achieved using a strong reducing agent, $\mathrm{NaBH}_{4}$.

A procedure adapted from Jana et al. was used for the synthesis of citrate-stabilized silver nanoparticles [40]. In short, $100 \mu \mathrm{L}$ of $0.05 \mathrm{M} \mathrm{AgNO}_{3}$ was combined with $100 \mu \mathrm{L}$ of $0.05 \mathrm{M}$ of sodium citrate dihydrate, followed by dilution of the mixture to $20 \mathrm{~mL}$ with deionized water. Subsequently, the silver was reduced with $200 \mu \mathrm{L}$ of ice cold $0.05 \mathrm{M} \mathrm{NaBH}_{4}$ producing a yellow/orange solution indicating the presence of silver nanoparticles $(d=4.0 \pm 1.0 \mathrm{~nm})$.

2.5. Characterization of Garlic Extract and Nanoparticle Surface Chemistry. High-performance liquid chromatography (HPLC) was used to characterize the water soluble molecules present in garlic extract and determine the silver nanoparticle stabilizing surface chemistries. All HPLC samples were passed through a $20 \mathrm{~nm}$ pore diameter Anotop 10 Whatman syringe filter to remove any particulates present in solution and protect the detection systems. HPLC with UV and RI detectors provided the retention times for fructose and sucrose $(50 \mathrm{mM}$ stock solutions were prepared in water for each sugar). The retention time for each sugar was then compared to the garlic extract and the nanoparticle surface chemistries.

Stabilizing molecules bound to the silver nanoparticle surface were characterized by HPLC. First, the nanoparticles were washed (centrifuged until all nanoparticles precipitated) and redispersed in deionized water. The washing process was repeated twice to ensure that no unbound molecules remained in the nanoparticle dispersion. Next, nanoparticles were digested by adding dilute nitric acid, turning the solution clear, and releasing the surface bound stabilizing molecules into solution. The resulting solution was then subjected to HPLC.

2.6. Stability of Silver Nanoparticles. Stability of the citrate and garlic extract capped nanoparticles was investigated by adding $1 \mathrm{~mL}$ of nanoparticle dispersion to $1 \mathrm{~mL}$ of DMEM high-modified biological media. Additional experiments with DMEM and MEM biological media were performed by adding $4 \mathrm{~mL}$ of media to $1 \mathrm{~mL}$ of nanoparticle dispersion. UV-VIS measurements were performed over time for both the citrate and garlic extract stabilized nanoparticles. Nanoparticle resistance to oxidation was measured by UVVIS before and after the addition ( $\sim 5 \mathrm{~min})$ of $100 \mu \mathrm{L}$ of $30 \%$ $\mathrm{H}_{2} \mathrm{O}_{2}$ to $5 \mathrm{~mL}$ silver nanoparticle dispersion.

2.7. Cell Culture. Two cell types were used in this study: NIH 3T3 fibroblasts cell line cells and primary rat aortic vascular smooth muscle cells (VSMCs). The 3T3 fibroblasts were thawed and plated in accordance with established protocols. The primary VSMCs were isolated from the aorta of adult Sprague Dawley rats; VSMCs were used between passage 5 and 8. Cells were cultured in Dulbecco's modified Eagle medium (DMEM) with 10\% fetal bovine serum (FBS) and $1 \%$ antibiotic-antimycotic solution on tissue-culturetreated polystyrene t-75 flasks. Cells were maintained in an incubator at $37^{\circ} \mathrm{C}$ and $5 \% \mathrm{CO}_{2}$, and media was replaced 

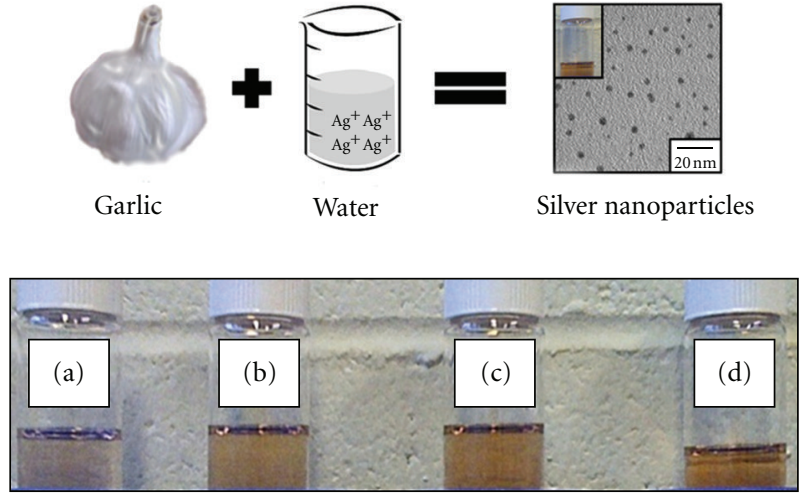

FIGURE 1: Representative images of silver nanoparticle dispersions synthesized with varying amounts of garlic extract solution at $25^{\circ} \mathrm{C}$ after a $48 \mathrm{hr}$ reaction time and purification by centrifugation (a) $1.0 \mathrm{~mL}$, (b) $1.5 \mathrm{~mL}$, (c) $2.0 \mathrm{~mL}$, and (d) $2.5 \mathrm{~mL}$.

every $48 \mathrm{hr}$. At $80 \%$ confluency, the cells were trypsinized with $0.25 \%$ trypsin and $0.02 \%$ ethyldiaminetetaacetic acid (EDTA) before being plated for cytotoxicity assays.

2.8. Cytotoxicity Assay. Cells were seeded in a 96-well plate at a density of 10,000 cells per well with $250 \mu \mathrm{L}$ of media. $25 \mu \mathrm{L}$ of either garlic extract prepared silver nanoparticles suspension or control particle-free phosphate-buffered saline was added to the wells. This resulted in a $25-50 \mu \mathrm{g} / \mathrm{mL}$ concentration of particles in each test well. Cells were cultured in the test solutions for $48 \mathrm{hr}$. The Promega CytoTox 96 nonradioactive cytotoxicity assay was used as detailed per the manufacturer instructions. The lysis solution (LS) was added at a ratio of $15 \mu \mathrm{L}$ LS per $100 \mu \mathrm{L}$ media, and the cells were incubated for $60 \mathrm{~min}$. Subsequently, $50 \mu \mathrm{L}$ of the supernatant was transferred to the 96-well plate enzymatic assay, where $50 \mu \mathrm{L}$ of the reconstituted substrate mix was added to each well. The plate was protected from light and incubated at room temperature for $30 \mathrm{~min}$. Lastly, $50 \mu \mathrm{L}$ of the stop solution was added to each well, and absorbance readings were taken at $490 \mathrm{~nm}$ to determine the amount of lactate dehydrogenase (LDH) released from live cells when lysed. The LDH is converted to a red formazan product by an enzymatic reaction with the substrate mix. The red product formed is directly proportional to the number of cells lysed, which can be quantified by recording absorbance at $490 \mathrm{~nm}$.

\section{Results and Discussion}

3.1. Nanoparticle Synthesis and Characterization. Nanoparticle size and size-distribution was found to be a function of the garlic extract concentration used during nanoparticle synthesis. Figure 1 shows an image of the silver nanoparticle dispersions with increasing garlic extract amounts. Representative TEM images and histograms are shown in Figure 2 for silver nanoparticles prepared using $1.0 \mathrm{~mL}$ and $2.0 \mathrm{~mL}$ of garlic extract, respectively. Figure 3(a) is the corresponding UV-VIS spectra for the nanoparticle dispersions shown in
Figure 1; the increase in color intensity (Figure 1) and UVVIS absorbance (Figure 3(a)) are attributed to the increase in nanoparticle size. UV-VIS absorbance measurements over one week after synthesis showed no variation in absorbance, suggesting that nucleation and growth occurs within the first 48 hour period. Samples stored for more than 9 months remain stable in solution with no visible sign of precipitation, aggregation, or oxidation.

The UV-VIS absorbance peak was fit with a Gaussian curve with a maximum at $404 \mathrm{~nm}$. Noticeable peak broadening and increases in absorbance intensity are evident in Figure 3(a). The peak broadening is attributed to an increase in polydispersity as a result of increased garlic extract solution employed during synthesis. According to Mie scattering theory, a decrease in FWHM suggests an increase in silver nanoparticle core-diameter [41]. Increased garlic extract concentration from $1.0 \mathrm{~mL}$ to $2.0 \mathrm{~mL}$ in the nanoparticle synthesis yielded peak broadening with an increase in FWHM from 118 to $134 \mathrm{~nm}$. TEM analysis of the garlic extract-stabilized silver nanoparticles confirms a slight increase in nanoparticle size from $3.7 \pm 0.9 \mathrm{~nm}$ for $1.0 \mathrm{~mL}$ extract, $3.8 \pm 1.3 \mathrm{~nm}$ for $1.5 \mathrm{~mL}$ extract, and $4.1 \pm 1.5 \mathrm{~nm}$ for $2.0 \mathrm{~mL}$ extract. Corresponding polydispersities increase from $25 \%$ to $33 \%$ to $36 \%$ with increased garlic extract concentration. Addition of $2.5 \mathrm{~mL}$ garlic extract in nanoparticle synthesis produced the largest UV-VIS absorbance intensity and a FWHM of $127 \mathrm{~nm}$, an average diameter of $6.2 \pm$ $2.7 \mathrm{~nm}$ and polydispersity of $43 \%$ determined by TEM. Sileikaite et al. also observed increases in UV-VIS absorbance peak FWHM that correspond to increases in polydispersity for citrate-stabilized silver nanoparticles [42]. Jana et al. observed similar results for oleic acid stabilized $\mathrm{Fe}_{3} \mathrm{O}_{4}$, where larger quantities of oleic acid were shown to produce larger diameter nanocrystals [43]. Overall, lower garlic extract concentrations yield smaller and more monodisperse silver nanoparticle populations; consistent with previous work where tailoring the reducing agent and/or stabilizing ligand concentrations affords control over nanoparticle size and size-distribution [15, 44-46].

In addition to controlling nanoparticle size and sizedistribution with garlic extract concentration, reaction temperature was found to impact nanoparticle size, polydispersity, and reaction kinetics. At $60^{\circ} \mathrm{C}$ and $1.5 \mathrm{~mL}$ of garlic extract, nanoparticles were synthesized in $15 \mathrm{~min}$, compared to $2 \mathrm{hr}$ at $25^{\circ} \mathrm{C}$. UV-VIS analysis showed a plasmon resonance peak centered at $404 \mathrm{~nm}$ for both the ambient and elevated temperatures. The FWHM value obtained from a Gaussian fit of the UV-VIS spectra was determined to be $133 \mathrm{~nm} ; 10 \%$ broader than the $25^{\circ} \mathrm{C}$ synthesis, indicating increased polydispersity and/or particle diameter. TEM analysis yielded $4.4 \pm 1.5 \mathrm{~nm}$ diameter particles with $35 \%$ polydispersity. UV-VIS analysis confirmed that at the same extract concentration, the elevated temperature produced a slightly larger and more polydisperse population of silver nanoparticles. The increase in size and polydispersity is likely due to variation in the nucleation and growth rates of the nanoparticles during synthesis. Despite a slightly increased polydispersity at elevated synthesis temperature, nanoparticle formation occurs at a faster rate and yields 

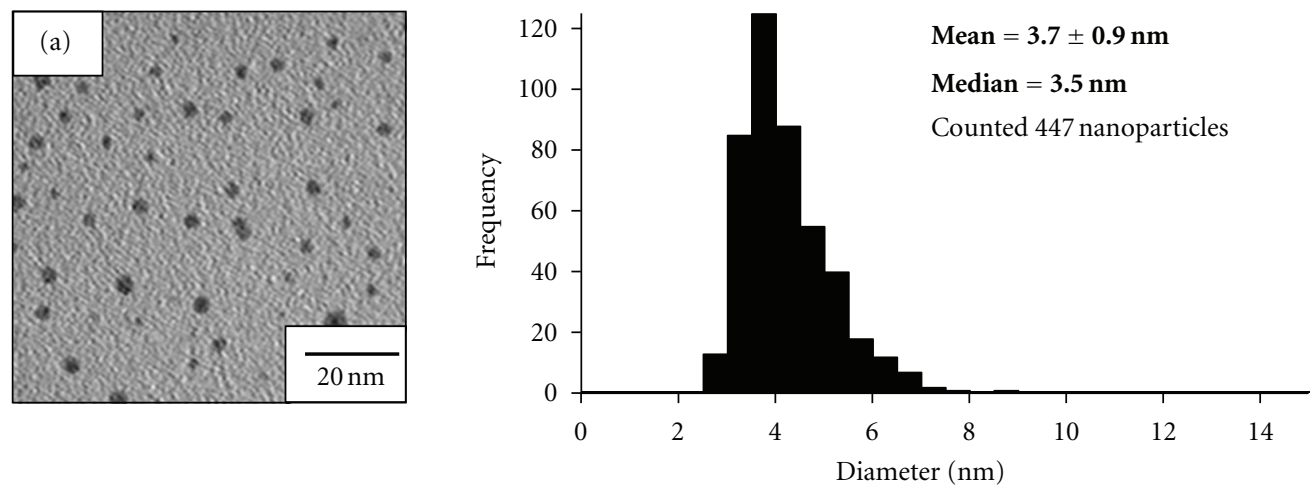

(a)
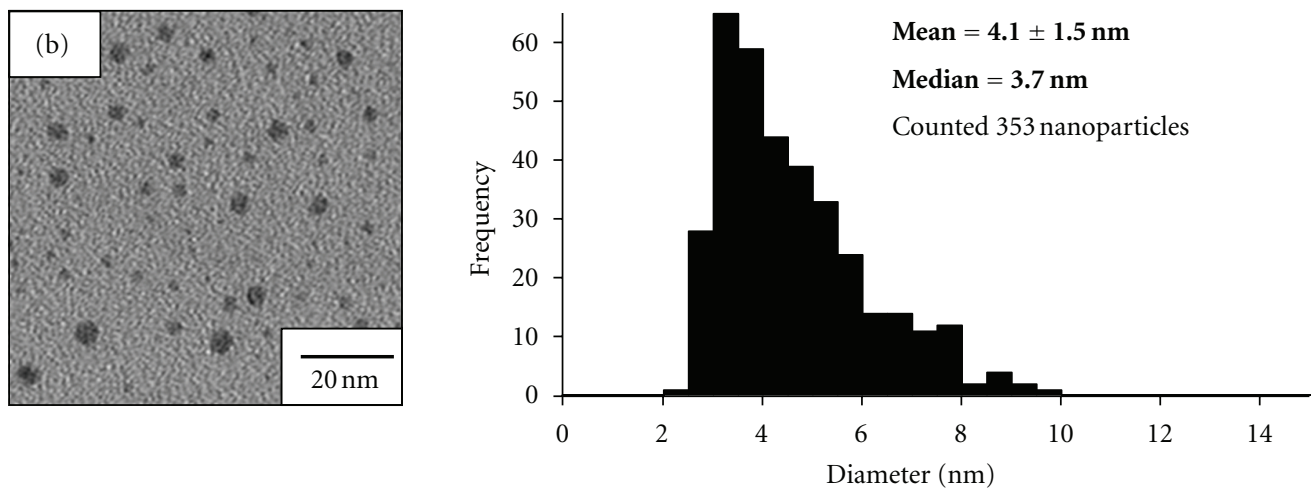

(b)

FIGURE 2: Representative TEM images and histograms for silver nanoparticles synthesized using garlic extract (a) $1.0 \mathrm{~mL}$ of garlic extract and (b) $2.0 \mathrm{~mL}$ of garlic extract.

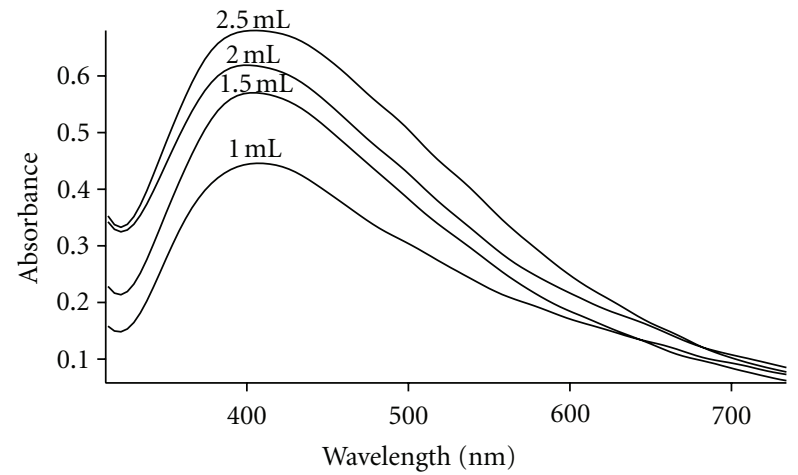

(a)

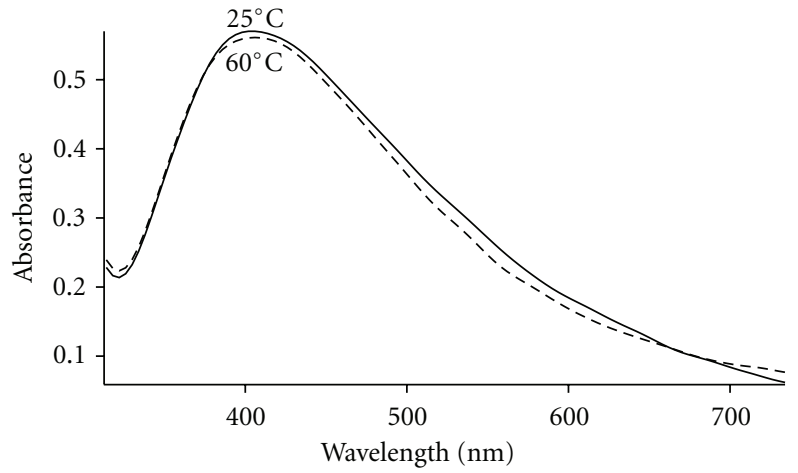

(b)

FIGURE 3: UV-VIS absorbance spectra of silver nanoparticles prepared using (a) varying amounts garlic extract (1.0, 1.5, 2.0, and 2.5 mL) and (b) $1.5 \mathrm{~mL}$ garlic extract at varying temperature $\left(25\right.$ and $\left.60^{\circ} \mathrm{C}\right)$.

similar concentrations of nanoparticles, as inferred from the UV-VIS absorbance intensity in Figure 3(b). Kasture et al. demonstrated that increased temperatures enabled reduced synthesis times for silver nanoparticles stabilized by sophorolipids in water [47].
To elucidate the active chemical species in the garlic extract, ATR-FTIR spectra (Figure 4(a)) show large $-\mathrm{OH}$ and $-\mathrm{CH}$ stretches obtained for the dried garlic extract (3300 and $2930 \mathrm{~cm}^{-1}$ ) and garlic extract prepared silver nanoparticles $\left(3270\right.$ and $\left.2930 \mathrm{~cm}^{-1}\right)$. The observed $-\mathrm{OH}$ 


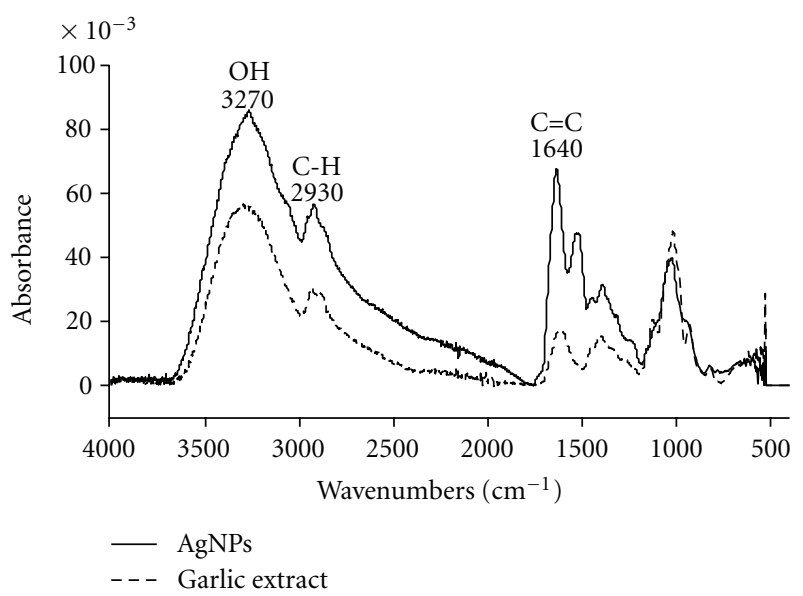

(a)

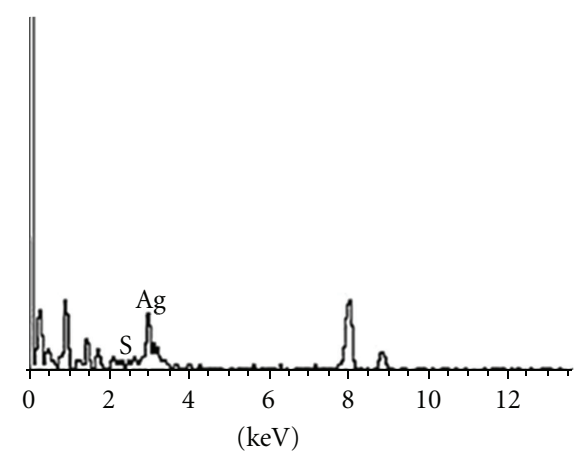

(b)

FIGURE 4: (a) representative ATR-FTIR spectra from dried garlic extract and dried silver nanoparticles synthesized using garlic extract. (b) EDX spectra of garlic extract prepared silver nanoparticles obtained from FE SEM.

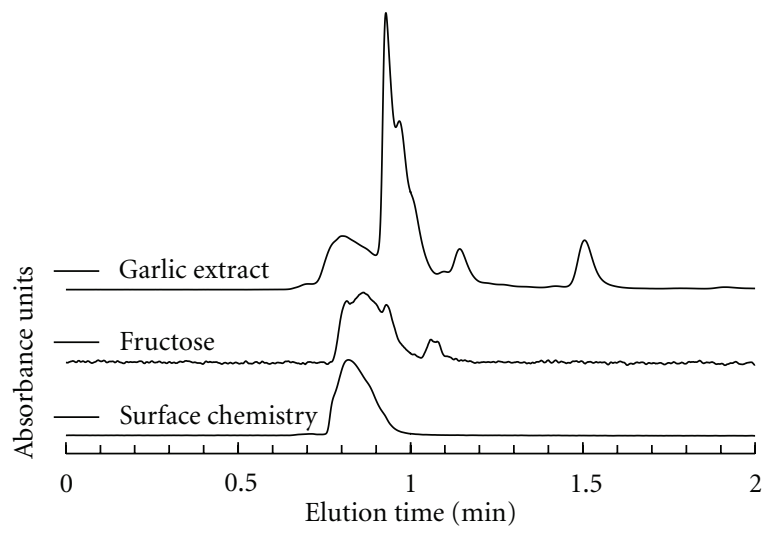

FIgURE 5: HPLC-UV chromatograms for sucrose, fructose, garlic extract, and isolated surface molecules previously bound to the surface of silver nanoparticles.

and $-\mathrm{CH}$ peaks are characteristic of sugars present in the garlic extract solution and nanoparticle dispersion. Sucrose and fructose are the primary nonstructural sugars that are readily extracted from garlic [48] and likely function as both the reducing agent and stabilizing chemistries. This theory is supported by recent work which shows that sucrose and fructose can function as reducing agents for the synthesis of aqueous dispersions of silver nanoparticles [49] as well as stabilizing ligands for various metal nanoparticles (e.g., Au, $\mathrm{Ag}, \mathrm{Pd}$, and $\mathrm{Pt}$ ) [13-15, 40].

HPLC spectra for fructose and sucrose standards with respective retention times of 1.21 and 1.20 min were determined with a refractive index (RI) detector. HPLC-RI of the garlic extract demonstrated a notably broader retention peak centered at $1.15 \mathrm{~min}$ that overlapped for the sucrose and fructose. A retention time of $1.22 \mathrm{~min}$ was measured for the digested nanoparticle solution, indicating that water soluble carbohydrates extracted from garlic were bound to the

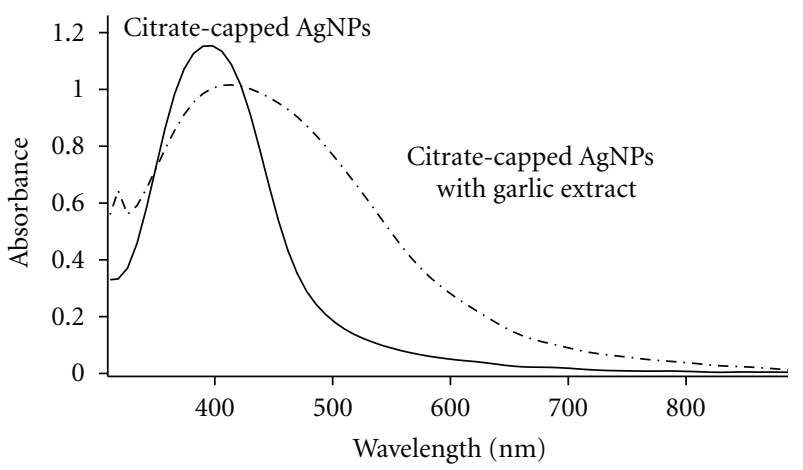

FIGURE 6: UV-VIS spectra for silver nanoparticles stabilized by citrate prior to and after the addition of garlic extract.

surface of the silver nanoparticles. Figure 5 shows the HPLCUV spectra obtained for fructose, garlic extract, and the digested nanoparticle solution that contains the nanoparticle surface chemistry. The garlic extract solution demonstrated the presence of at least five different species-though not surprising as garlic contains numerous phytochemicals, including allicin, which absorbs at $254 \mathrm{~nm}$ [50]. A broadand low-intensity peak was present in the surface chemistry solution with a retention time of $0.9 \mathrm{~min}$ and suggests that organosulfur compounds were also bound to the silver nanoparticle surface.

EDX chemical analysis (Figure 4) performed on a dried film of garlic extract prepared nanoparticles shows the presence of sulfur in the garlic extract, which is expected as organosulfur compounds (primarily allyl sulfides) are readily extracted from garlic using either water or ethanol [51]. Adding garlic extract solution to citrate-stabilized silver nanoparticles demonstrated an increase in FWHM $(57 \%)$, decrease in absorbance, and a red shift in wavelength absorbance of $16 \mathrm{~nm}$ (see Figure 6). Cai et al. attributed 

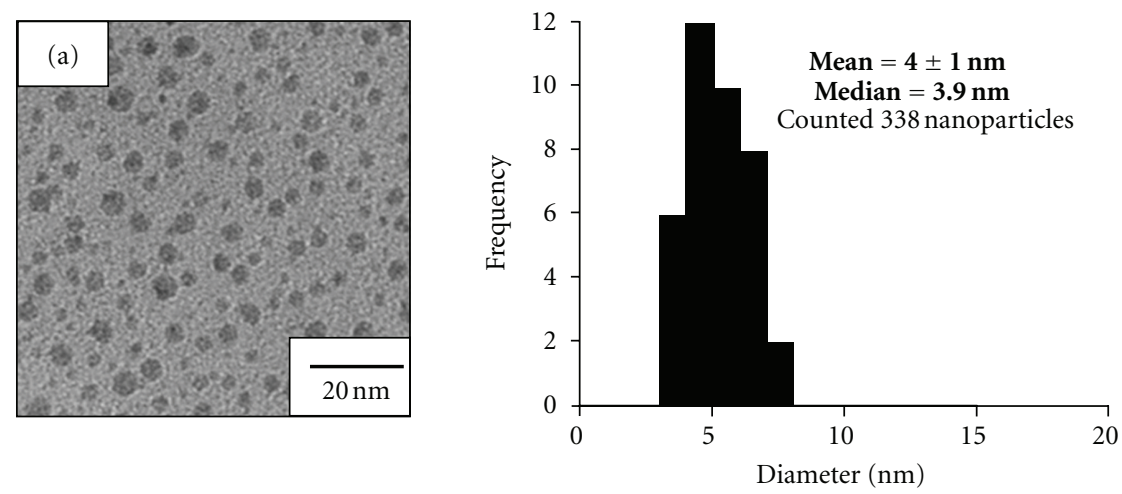

(a)
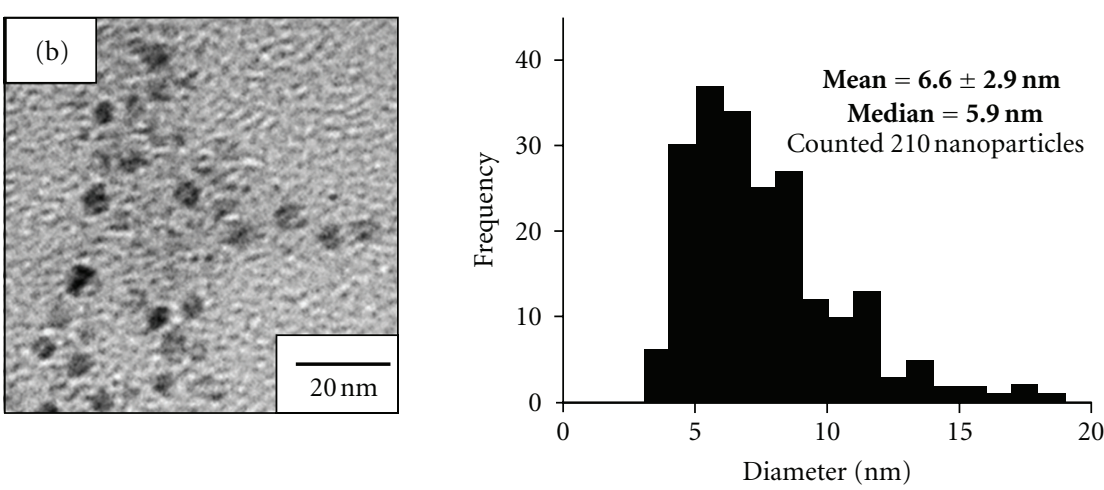

(b)

FIGURE 7: Representative TEM images and histograms for silver nanoparticles synthesized citrate (a) before and (b) after garlic extract addition.

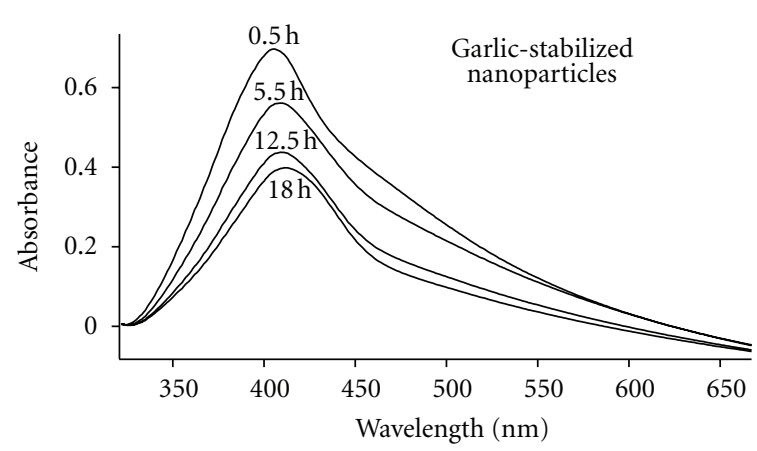

(a)

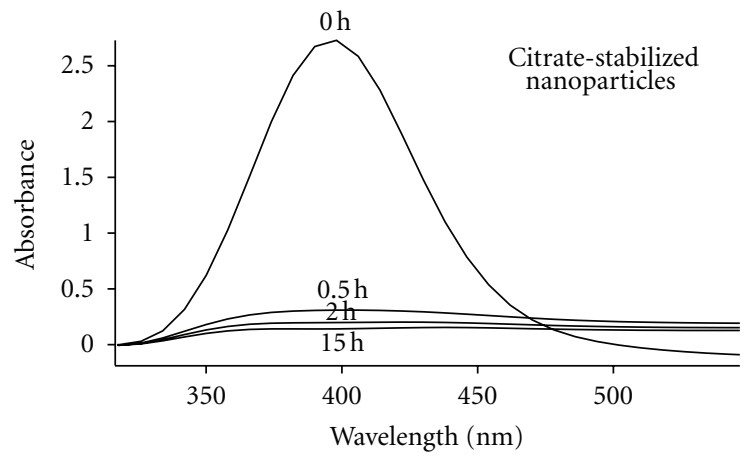

(b)

FIGURE 8: UV-VIS spectra for silver nanoparticles stabilized by (a) garlic extract and (b) citrate in the presence of DMEM/high modified cell culture media as a function of time.

large shifts in UV-VIS absorbance and increases in FWHM to a change in surface chemistry for unmodified silver nanoparticles, when hexanethiol was added to the dispersion [52]. The organosulfur compounds present in the garlic extract may modify the surface chemistry of the silver nanoparticles through thiolate bonding. The variation in UV-VIS spectra may also be due to a second nucleation and growth stage caused by the fructose and sucrose present in the garlic extract. TEM images obtained after garlic extract was added to the citrate stabilized nanoparticles show an increase in both size and polydispersity (see Figure 7). The mean core diameter was measured to be $6.6 \pm 2.9 \mathrm{~nm}$ (44\% polydispersity). Further chemical analysis would be beneficial to determine if additional stabilizing chemistries are present, other than the observed carbohydrate sugars and organosulfur compounds $[51,53]$.

Zeta-potential measurements were performed for direct comparison to conventional studies of nanoparticle stability. Zeta-potential analysis demonstrated that the garlic extract and citrate-stabilized nanoparticles had negative charges of 


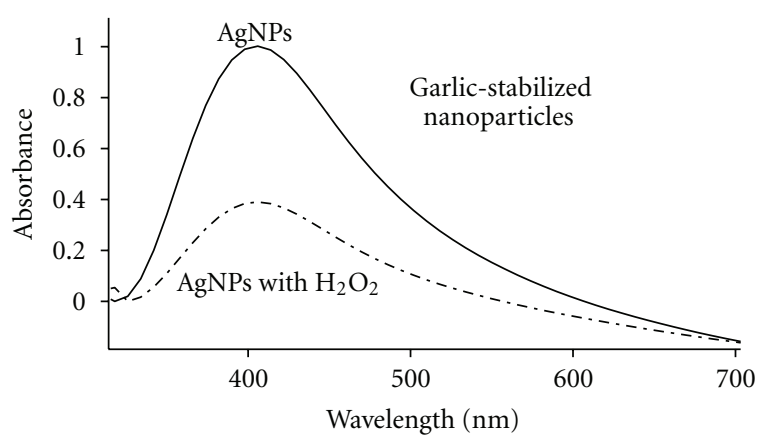

(a)

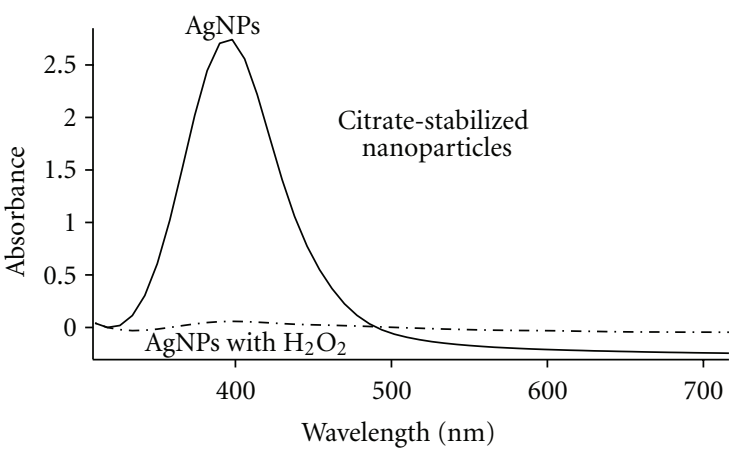

(b)

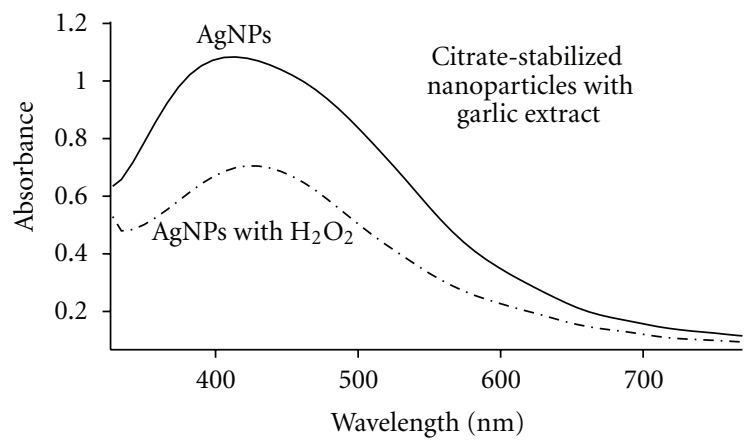

(c)

FIGURE 9: UV-VIS spectra for silver nanoparticles stabilized by (a) garlic extract, (b) citrate, and (c) citrate with garlic extract in the presence of $30 \% \mathrm{H}_{2} \mathrm{O}_{2}$.

$-31 \mathrm{mV}$ and $-30 \mathrm{mV}$, respectively. Both silver nanoparticle dispersions were sufficiently charged to maintain stability in solution over long periods of time (both chemistries have maintained stable dispersions at room temperature over several months). The zeta-potential measurement of the garlic extract stabilized silver nanoparticles is consistent with other sugar-stabilized silver and gold nanoparticles including citrate [54, 55], maltose [56], gum acacia (a Polysaccharide) [57], glucose [58], and galactose [58].

3.2. Nanoparticle Stability: Resistance to Aggregation and Oxidation. Applications of silver nanoparticles in the biomedical field and commercial industry are growing rapidly due to the unique optical and antibacterial properties [59-62]. Therefore, understanding nanoparticle stability at biological conditions and in biological media is becoming increasingly critical. We have studied the stability of garlic extractstabilized silver nanoparticles in biological cell culture media (DMEM/highly modified and MEM). We have also examined nanoparticle oxidation resistance against $\mathrm{H}_{2} \mathrm{O}_{2}$ in order to predict nanoparticle behavior in the presence of large quantities of ROS. Understanding nanoparticle aggregation and oxidation at biological conditions will provide insight to in vivo nanoparticle behavior.

Silver nanoparticles stabilized with the garlic extract are compared to commonly synthesized citrate-stabilized silver nanoparticles $(d=4.0 \pm 1.0 \mathrm{~nm})$. Figure 8 shows UV-VIS spectra for silver nanoparticles synthesized with $1.5 \mathrm{~mL}$ garlic extract as a function of time after $50 \%$ by volume addition of nanoparticle dispersion to DMEM biological media. Citratestabilized silver nanoparticles were investigated for comparison. Figure 8(a) shows the UV-VIS absorbance spectra for the garlic extract-stabilized silver nanoparticles, exhibiting a decrease over $18 \mathrm{hr}$. The decrease in plasmon resonance is the result of reversible clustering, as gentle mixing of the liquid readily resuspends the nanoparticles back into solution. After $18 \mathrm{hr}$ of incubation in DMEM media, the characteristic plasmon resonance peak centered at $404 \mathrm{~nm}$ is still prominent. Visual inspection of the garlic stabilized silver nanoparticles showed no signs of aggregation. Increasing the ratio of DMEM to nanoparticle dispersion (4:1 by volume) provided similar results to the $1: 1$ ratio. Addition of garlic stabilized silver nanoparticles to MEM $\alpha$ biological media at a ratio of $4: 1$ by volume also showed a decrease in UV-VIS absorbance; however, no red shift in UV-VIS absorbance or aggregation was observed.

Comparatively, Figure 8(b) shows a significant decrease in absorbance intensity for citrate-stabilized nanoparticles at $404 \mathrm{~nm}$ in less than $30 \mathrm{~min}$ after addition to DMEM biological media at a $1: 1$ volume ratio. At $15 \mathrm{hr}$ of incubation in DMEM biological media, the nanoparticles have completely and irreversibly precipitated out of solution. The significantly enhanced stability of garlic extract stabilized silver nanoparticles in biological media makes them a potential candidate for future in vivo application and studies to differentiate the toxicity effects of $\mathrm{Ag}^{+}$and nanosilver $[23,54]$. 


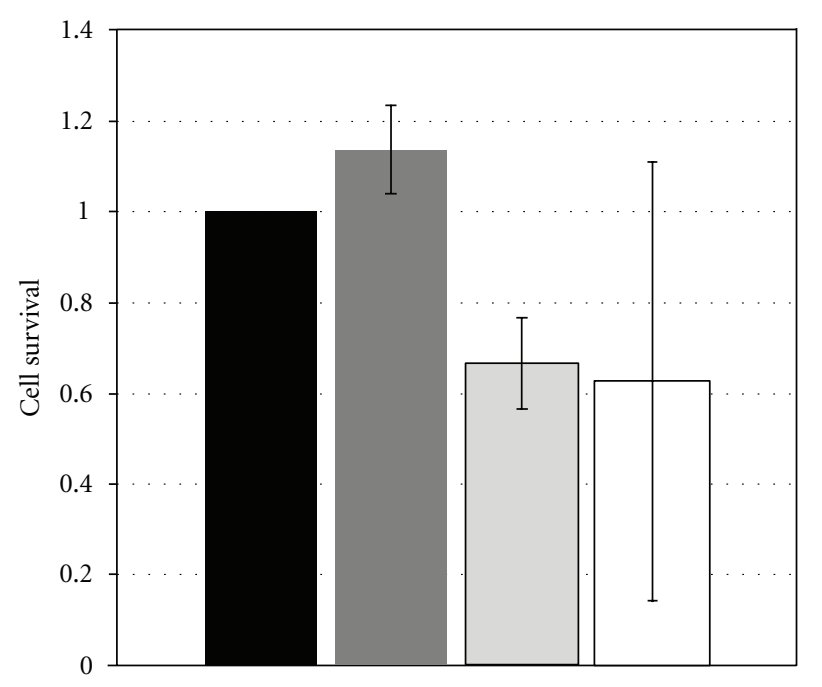

- Control
- Nanoparticles (low concentration)
$\square$ Nanoparticles (high concentration)
$\square$ Garlic extract (high concentration)

FIgure 10: Cytotoxicity assay for VSMCs treated at low $(25 \mu \mathrm{g} / \mathrm{mL})$ and high $(50 \mu \mathrm{g} / \mathrm{mL})$ nanoparticle concentrations. The control VSMCs (black bar) were treated with equivalent FBS aliquots, and garlic extract control (white bar) demonstrated cytotoxicity for treatment with an equivalent concentration of garlic extract for the $50 \mu \mathrm{g} / \mathrm{mL}$ nanoparticle concentration.

In addition to enhanced compatibility with biological media, the garlic extract-stabilized silver nanoparticles were tested for oxidation resistance to $\mathrm{H}_{2} \mathrm{O}_{2}$ exposure. Figure 9 shows the UV-VIS spectra of citrate and garlic extract stabilized silver nanoparticles exposed to $\mathrm{H}_{2} \mathrm{O}_{2}$. Fitting the UV-VIS spectra in Figure 9(a) demonstrates a red shift $(d=$ $4 \mathrm{~nm})$ in SPR absorbance and an increase in FWHM $(d=$ $24 \mathrm{~nm}$ ) suggesting an increase in polydispersity and/or size. Upon $\mathrm{H}_{2} \mathrm{O}_{2}$ addition, the citrate-stabilized nanoparticle dispersion immediately turns clear. The loss of SPR absorbance (Figure 9(b)) demonstrates poor oxidation resistance and indicates $\mathrm{Ag}^{0}$ oxidation to $\mathrm{Ag}^{+}$for the citrate stabilized silver nanoparticles. The SPR absorbance peak for the garlic extract-stabilized silver nanoparticles is still present after $\mathrm{H}_{2} \mathrm{O}_{2}$ addition, though at a lower intensity.

The oxidation resistance to $\mathrm{H}_{2} \mathrm{O}_{2}$ may be attributed to the phytochemical compounds present in the aqueous garlic extract, more explicitly allicin (diallyl-thiosulfinate) and other allyl sulfides [51]. To confirm this hypothesis, garlic extract was added to the citrate-stabilized silver nanoparticles, and the oxidation resistance was measured by UV-VIS. We observed a significant increase in oxidation resistance for citrate-stabilized silver nanoparticles when adding garlic extract to the dispersion, Figure 9(c). Allicin is the primary organosulfur compound found in garlic [37] and is credited with having strong antioxidant properties including scavenging hydroxyl radicals [63] and suppressing oxygen radical formation [64]. It is unclear if the freely available allyl sulfides dispersed in solution or bound to the silver nanoparticle surface provide the enhanced nanoparticle oxidation resistance.

3.3. Cytotoxicity Assay on VSMCs and NIH 3 T3 Fibroblasts. NIH 3T3 fibroblasts treated with nanoparticles were not significantly different from control fibroblasts treated with PBS alone. The Promega CytoTox 96 assay showed no significant difference between the cell survival rates for the control cells against the nanoparticle treated cells. Vascular smooth muscle cells (VSMCs) demonstrated a $13.5 \%$ increase in proliferation when treated with $25 \mu \mathrm{g} / \mathrm{mL}$ of garlic nanoparticles over the untreated cells (Figure 10). This was significantly higher than the control with $P<0.05$. While this indicates no cytotoxicity, nanoparticle exposure may be influencing VSMC behavior by causing a shift towards a more proliferative phenotype. When the cells were treated with an increased nanoparticle concentration $(50 \mu \mathrm{g} / \mathrm{mL})$, some cytotoxicity was observed; cell survivability decreased by $1 / 3$ as shown by the CytoTox assay. However, garlic extract by itself also showed similar results. Therefore, these cytotoxicity results could have been due to unreacted garlic extract components in the solution rather than from the particles themselves.

\section{Conclusions}

We have demonstrated a one-pot green synthesis of silver nanoparticles that do not exhibit toxicity for VSMCs and NIH 3T3 fibroblasts. This investigation provides evidence that garlic extract-stabilized nanoparticles may be ideal candidates for future studies exploring their use in biomedical applications. This synthesis procedure offers a cost-effective and green alternative to traditional protocols that may be readily scaled up for industry as a result of the low synthesis temperatures and time required. We show that controlling the quantity of the garlic extract employed during synthesis enables some variation in nanoparticle size and sizedistribution (approximately 4 and $6 \mathrm{~nm}$ in core-diameter). At $60^{\circ} \mathrm{C}$, the synthesis time was reduced, but an increase in the size and polydispersity was observed. ATR-FTIR and EDX chemical analysis suggest that the reducing and stabilizing agents are likely sugars (fructose and/or sucrose), where costabilization may also occur by the organosulfur compounds present in the garlic extract. The silver nanoparticles prepared using garlic extract demonstrated compatibility with frequently used biological media. Enhanced oxidation resistance was also observed, when $\mathrm{H}_{2} \mathrm{O}_{2}$ was added to nanoparticle dispersions. Strong oxidation resistance of the garlic extract prepared silver nanoparticles is attributed to the presence of organosulfur compounds in the form of allyl sulfides as demonstrated by EDX analysis and supported by HPLC-UV spectra. 


\section{Acknowledgment}

This paper was sponsored by NSF Grant numbers EEC082443 and EEC-0602040 and by NIH NHLBI Grant number K25 HL092228. Fellowship funding at the time of this work was provided by the South East Alliance for Graduate Education and the Professoriate (SEAGEP) on the National Science Foundation award HRD-0450279.

\section{References}

[1] V. H. Grassian, "When size really matters: size-dependent properties and surface chemistry of metal and metal oxide nanoparticles in gas and liquid phase environments," Journal of Physical Chemistry C, vol. 112, no. 47, pp. 18303-18313, 2008.

[2] P. K. Jain, K. S. Lee, I. H. El-Sayed, and M. A. El-Sayed, "Calculated absorption and scattering properties of gold nanoparticles of different size, shape, and composition: applications in biological imaging and biomedicine," Journal of Physical Chemistry B, vol. 110, no. 14, pp. 7238-7248, 2006.

[3] C. Liu and Z. J. Zhang, "Size-dependent superparamagnetic properties of Mn spinel ferrite nanoparticles synthesized from reverse micelles," Chemistry of Materials, vol. 13, no. 6, pp. 2092-2096, 2001.

[4] X. H. N. Xu, S. Huang, W. Brownlow, K. Salaita, and R. B. Jeffers, "Size and temperature dependence of surface plasmon absorption of gold nanoparticles induced by tris $\left(2,2^{\prime}\right.$ bipyridine)ruthenium(II)," Journal of Physical Chemistry B, vol. 108, no. 40, pp. 15543-15551, 2004.

[5] D. Manno, E. Filippo, M. Di Giulio, and A. Serra, "Synthesis and characterization of starch-stabilized Ag nanostructures for sensors applications," Journal of Non-Crystalline Solids, vol. 354, no. 52-54, pp. 5515-5520, 2008.

[6] Y. J. Kim, Y. S. Yang, S. -C. Ha et al., "Mixed-ligand nanoparticles of chlorobenzenemethanethiol and n-octanethiol as chemical sensors," Sensors and Actuators B, vol. 106, no. 1, pp. 189-198, 2005.

[7] A. Prakash, J. Ouyang, J. L. Lin, and Y. Yang, "Polymer memory device based on conjugated polymer and gold nanoparticles," Journal of Applied Physics, vol. 100, no. 5, Article ID 054309, 2006.

[8] A. D. LaLonde, M. G. Norton, D. Zhang et al., "Controlled growth of gold nanoparticles on silica nanowires," Journal of Materials Research, vol. 20, no. 11, pp. 3021-3027, 2005.

[9] M. Brust, M. Walker, D. Bethell, D. J. Schiffrin, and R. Whyman, "Synthesis of thiol-derivatised gold nanoparticles in a two-phase liquid-liquid system," Journal of the Chemical Society, Chemical Communications, no. 7, pp. 801-802, 1994.

[10] A. P. Herrera, O. Resto, J. G. Briano, and C. Rinaldi, "Synthesis and agglomeration of gold nanoparticles in reverse micelles," Nanotechnology, vol. 16, no. 7, pp. S618-S625, 2005.

[11] C. L. Kitchens, M. C. McLeod, and C. B. Roberts, "Chloride ion effects on synthesis and directed assembly of copper nanoparticles in liquid and compressed alkane microemulsions," Langmuir, vol. 21, no. 11, pp. 5166-5173, 2005.

[12] M.-L. Wu and L.-B. Lai, "Synthesis of Pt/Ag bimetallic nanoparticles in water-in-oil microemulsions," Colloids and Surfaces A, vol. 244, no. 1-3, pp. 149-157, 2004.

[13] J. Liu, J. Sutton, and C. B. Roberts, "Synthesis and extraction of monodisperse sodium carboxymethylcellulose-stabilized platinum nanoparticles for the self-assembly of ordered arrays,"
Journal of Physical Chemistry C, vol. 111, no. 31, pp. 1156611576, 2007.

[14] J. Liu, M. Anand, and C. B. Roberts, "Synthesis and extraction of $\beta$-D-glucose-stabilized au nanoparticles processed into lowdefect, wide-area thin films and ordered arrays using $\mathrm{CO}_{2}$ expanded liquids," Langmuir, vol. 22, no. 9, pp. 3964-3971, 2006.

[15] J. Liu, F. He, T. M. Gunn, D. Zhao, and C. B. Roberts, "Precise seed-mediated growth and size-controlled synthesis of palladium nanoparticles using a green chemistry approach," Langmuir, vol. 25, no. 12, pp. 7116-7128, 2009.

[16] S. Y. Moon, T. Kusunose, and T. Sekino, "CTAB-assisted synthesis of size- and shape-controlled gold nanoparticles in SDS aqueous solution," Materials Letters, vol. 63, no. 23, pp. 2038-2040, 2009.

[17] Z. M. Sui, X. Chen, L. Y. Wang et al., "Capping effect of CTAB on positively charged Ag nanoparticles," Physica E, vol. 33, no. 2, pp. 308-314, 2006.

[18] S. C. Boca and S. Astilean, "Detoxification of gold nanorods by conjugation with thiolated poly(ethylene glycol) and their assessment as SERS-active carriers of Raman tags," Nanotechnology, vol. 21, no. 23, Article ID 235601, 2010.

[19] M. C. Urbina, S. Zinoveva, T. Miller, C. M. Sabliov, W. T. Monroe, and C. S. S. R. Kumar, "Investigation of magnetic nanoparticle-polymer composites for multiple-controlled drug delivery," Journal of Physical Chemistry C, vol. 112, no. 30, pp. 11102-11108, 2008.

[20] R. Bhattacharya, C. R. Patra, A. Earl et al., "Attaching folic acid on gold nanoparticles using noncovalent interaction via different polyethylene glycol backbones and targeting of cancer cells," Nanomedicine: Nanotechnology, Biology, and Medicine, vol. 3, no. 3, pp. 224-238, 2007.

[21] R. E. Rosensweig, "Heating magnetic fluid with alternating magnetic field," Journal of Magnetism and Magnetic Materials, vol. 252, no. 1-3, pp. 370-374, 2002.

[22] C. Greulich, S. Kittler, M. Epple, G. Muhr, and M. Köller, "Studies on the biocompatibility and the interaction of silver nanoparticles with human mesenchymal stem cells (hMSCs)," Langenbeck's Archives of Surgery, vol. 394, no. 3, pp. 495-502, 2009.

[23] J. Liu and R. H. Hurt, "Ion release kinetics and particle persistence in aqueous nano-silver colloids," Environmental Science and Technology, vol. 44, no. 6, pp. 2169-2175, 2010.

[24] M. Halter, J. L. Almeida, A. Tona, K. D. Cole, A. L. Plant, and J. T. Elliott, "A mechanistically relevant cytotoxicity assay based on the detection of cellular GFP," Assay and Drug Development Technologies, vol. 7, no. 4, pp. 356-365, 2009.

[25] C. Carlson, S. M. Hussein, A. M. Schrand et al., "Unique cellular interaction of silver nanoparticles: size-dependent generation of reactive oxygen species," Journal of Physical Chemistry B, vol. 112, no. 43, pp. 13608-13619, 2008.

[26] P. V. AshaRani, G. L. K. Mun, M. P. Hande, and S. Valiyaveettil, "Cytotoxicity and genotoxicity of silver nanoparticles in human cells," ACS Nano, vol. 3, no. 2, pp. 279-290, 2009.

[27] A. P. Leonov, J. Zheng, J. D. Clogston, S. T. Stern, A. K. Patri, and A. Wei, "Detoxification of gold nanorods by treatment with polystyrenesulfonate," ACS Nano, vol. 2, no. 12, pp. 24812488, 2008.

[28] P. T. Anastas and J. C. Warner, "Twelve Principles of Green Chemistry," 2010, http://www.epa.gov/sciencematters/ june2011/principles.htm.

[29] P. T. Anastas and J. C. Warner, Green Chemistry: Theory and Practice, Oxford University Press, New York, NY, USA, 1998. 
[30] D. Philip, "Honey mediated green synthesis of gold nanoparticles," Spectrochimica Acta A, vol. 73, no. 4, pp. 650-653, 2009.

[31] R. Shukla, S. K. Nune, N. Chanda et al., "Soybeans as a phytochemical reservoir for the production and stabilization of biocompatible gold nanoparticles," Small, vol. 4, no. 9, pp. 1425-1436, 2008.

[32] J. L. Gardea-Torresdey, E. Gomez, J. R. Peralta-Videa, J. G. Parsons, H. Troiani, and M. Jose-Yacaman, "Alfalfa sprouts: a natural source for the synthesis of silver nanoparticles," Langmuir, vol. 19, no. 4, pp. 1357-1361, 2003.

[33] S. S. Shankar, A. Rai, A. Ahmad, and M. Sastry, "Controlling the optical properties of lemongrass extract synthesized gold nanotriangles and potential application in infrared-absorbing optical coatings," Chemistry of Materials, vol. 17, no. 3, pp. 566-572, 2005.

[34] V. Smuleac, R. Varma, S. Sikdar, and D. Bhattacharyya, "Green synthesis of $\mathrm{Fe}$ and $\mathrm{Fe} / \mathrm{Pd}$ bimetallic nanoparticles in membranes for reductive degradation of chlorinated organics," Journal of Membrane Science, vol. 379, no. 1-2, pp. 131-137, 2011.

[35] R. Naganawa, N. Iwata, K. Ishikawa, H. Fukuda, T. Fujino, and A. Suzuki, "Inhibition of microbial growth by ajoene, a sulfur-containing compound derived from garlic," Applied and Environmental Microbiology, vol. 62, no. 11, pp. 4238-4242, 1996.

[36] P. Tedeschi, A. Maietti, M. Boggian, G. Vecchiati, and V. Brandolini, "Fungitoxicity of lyophilized and spray-dried garlic extracts," Journal of Environmental Science and Health $B$, vol. 42, no. 7, pp. 795-799, 2007.

[37] M. S. Rahman, "Allicin and other functional active components in garlic: health benefits and bioavailability," International Journal of Food Properties, vol. 10, no. 2, pp. 245-268, 2007.

[38] K. Srinivasan, "Spices as influencers of body metabolism: an overview of three decades of research," Food Research International, vol. 38, no. 1, pp. 77-86, 2005.

[39] M. D. Abramoff, P. J. Magalhaes, and S. Ram, "Image processing with imageJ," Biophotonics International, vol. 11, no. 7, pp. 36-41, 2004.

[40] N. R. Jana, L. Gearheart, and C. J. Murphy, "Wet chemical synthesis of high aspect ratio cylindrical gold nanorods," Journal of Physical Chemistry B, vol. 105, no. 19, pp. 40654067, 2001.

[41] D. K. Bhui, H. Bar, P. Sarkar, G. P. Sahoo, S. P. De, and A. Misra, "Synthesis and UV-vis spectroscopic study of silver nanoparticles in aqueous SDS solution," Journal of Molecular Liquids, vol. 145, no. 1, pp. 33-37, 2009.

[42] A. Šileikaite, J. Puišo, I. Prosyčevas, and S. Tamulevičius, "Investigation of silver nanoparticles formation kinetics during reduction of silver nitrate with sodium citrate," Medziagotyra, vol. 15, no. 1, pp. 21-27, 2009.

[43] N. R. Jana, Y. Chen, and X. Peng, "Size- and shape-controlled magnetic ( $\mathrm{Cr}, \mathrm{Mn}, \mathrm{Fe}, \mathrm{Co}, \mathrm{Ni}$ ) oxide nanocrystals via a simple and general approach," Chemistry of Materials, vol. 16, no. 20, pp. 3931-3935, 2004.

[44] X. Ji, X. Song, J. Li, Y. Bai, W. Yang, and X. Peng, "Size control of gold nanocrystals in citrate reduction: the third role of citrate," Journal of the American Chemical Society, vol. 129, no. 45, pp. 13939-13948, 2007.

[45] Y. Sun and Y. Xia, "Shape-controlled synthesis of gold and silver nanoparticles," Science, vol. 298, no. 5601, pp. 2176$2179,2002$.

[46] X. C. Jiang and M. P. Pileni, "Gold nanorods: influence of various parameters as seeds, solvent, surfactant on shape control," Colloids and Surfaces A, vol. 295, no. 1-3, pp. 228232, 2007.

[47] M. B. Kasture, P. Patel, A. A. Prabhune, C. V. Ramana, A. A. Kulkarni, and B. L. V. Prasad, "Synthesis of silver nanoparticles by sophorolipids: effect of temperature and sophorolipid structure on the size of particles," Journal of Chemical Sciences, vol. 120, no. 6, pp. 515-520, 2008.

[48] J. N. Losso and S. Nakai, "Molecular size of garlic fructooligosaccharides and fructopolysaccharides by matrix-assisted laser desorption ionization mass spectrometry," Journal of Agricultural and Food Chemistry, vol. 45, no. 11, pp. 43424346, 1997.

[49] S. K. Mehta, S. Chaudhary, and M. Gradzielski, "Time dependence of nucleation and growth of silver nanoparticles generated by sugar reduction in micellar media," Journal of Colloid and Interface Science, vol. 343, no. 2, pp. 447-453, 2010.

[50] P. Bocchini, C. Andalò, R. Pozzi, G. C. Galletti, and A. Antonelli, "Determination of diallyl thiosulfinate (allicin) in garlic (Allium sativum L.) by high-performance liquid chromatography with a post-column photochemical reactor," Analytica Chimica Acta, vol. 441, no. 1, pp. 37-43, 2001.

[51] E. Block, "The chemistry of garlic and onions," Scientific American, vol. 252, no. 3, pp. 114-119, 1985.

[52] M. Cai, J. Chen, and J. Zhou, "Reduction and morphology of silver nanoparticles via liquid-liquid method," Applied Surface Science, vol. 226, no. 4, pp. 422-426, 2004.

[53] J. C. Love, L. A. Estroff, J. K. Kriebel, R. G. Nuzzo, and G. M. Whitesides, "Self-assembled monolayers of thiolates on metals as a form of nanotechnology," Chemical Reviews, vol. 105, no. 4, pp. 1103-1169, 2005.

[54] S. Kittler, C. Greulich, J. Diendorf, M. Köller, and M. Epple, "Toxicity of silver nanoparticles increases during storage because of slow dissolution under release of silver ions," Chemistry of Materials, vol. 22, no. 16, pp. 4548-4554, 2010.

[55] M. D. Massich, D. A. Giljohann, A. L. Schmucker, P. C. Patel, and C. A. Mirkin, "Cellular response of polyvalent oligonucleotide-gold nanoparticle conjugates," ACS Nano, vol. 4, no. 10, pp. 5641-5646, 2010.

[56] A. Köth, J. Koetz, D. Appelhans, and B. Voit, "'Sweet' gold nanoparticles with oligosaccharide-modified poly(ethyleneimine)," Colloid and Polymer Science, vol. 286, no. 11, pp. 1317-1327, 2008.

[57] Y. N. Rao, D. Banerjee, A. Datta, S. K. Das, R. Guin, and A. Saha, "Gamma irradiation route to synthesis of highly redispersible natural polymer capped silver nanoparticles," $R a$ diation Physics and Chemistry, vol. 79, no. 12, pp. 1240-1246, 2010.

[58] I. Sur, D. Cam, M. Kahraman, A. Baysal, and M. Culha, "Interaction of multi-functional silver nanoparticles with living cells," Nanotechnology, vol. 21, no. 17, Article ID 175104, 2010.

[59] C. Marambio-Jones and E. M. V. Hoek, "A review of the antibacterial effects of silver nanomaterials and potential implications for human health and the environment," Journal of Nanoparticle Research, vol. 12, no. 5, pp. 1531-1551, 2010.

[60] V. K. Sharma, R. A. Yngard, and Y. Lin, "Silver nanoparticles: green synthesis and their antimicrobial activities," Advances in Colloid and Interface Science, vol. 145, no. 1-2, pp. 83-96, 2009.

[61] L. Kvítek, A. Panáček, J. Soukupová et al., "Effect of surfactants and polymers on stability and antibacterial activity of silver nanoparticles (NPs)," Journal of Physical Chemistry C, vol. 112, no. 15 , pp. 5825-5834, 2008.

[62] S. Shrivastava, T. Bera, A. Roy, G. Singh, P. Ramachandrarao, and D. Dash, "Characterization of enhanced antibacterial 
effects of novel silver nanoparticles," Nanotechnology, vol. 18, no. 22, Article ID 225103, 2007.

[63] K. Prasad, V. A. Laxdal, M. Yu, and B. L. Raney, "Antioxidant activity of allicin, an active principle in garlic," Molecular and Cellular Biochemistry, vol. 148, no. 2, pp. 183-189, 1995.

[64] E. I. Astashkin, O. A. Khokhlova, N. A. Til'kunova, D. Y. Zalepugin, M. G. Glezer, and S. V. Grachev, "Allicin suppresses the production of oxygen radicals by human neutrophils induced by various stimulating agents." Doklady Biological Sciences, vol. 389, pp. 188-191, 2003. 

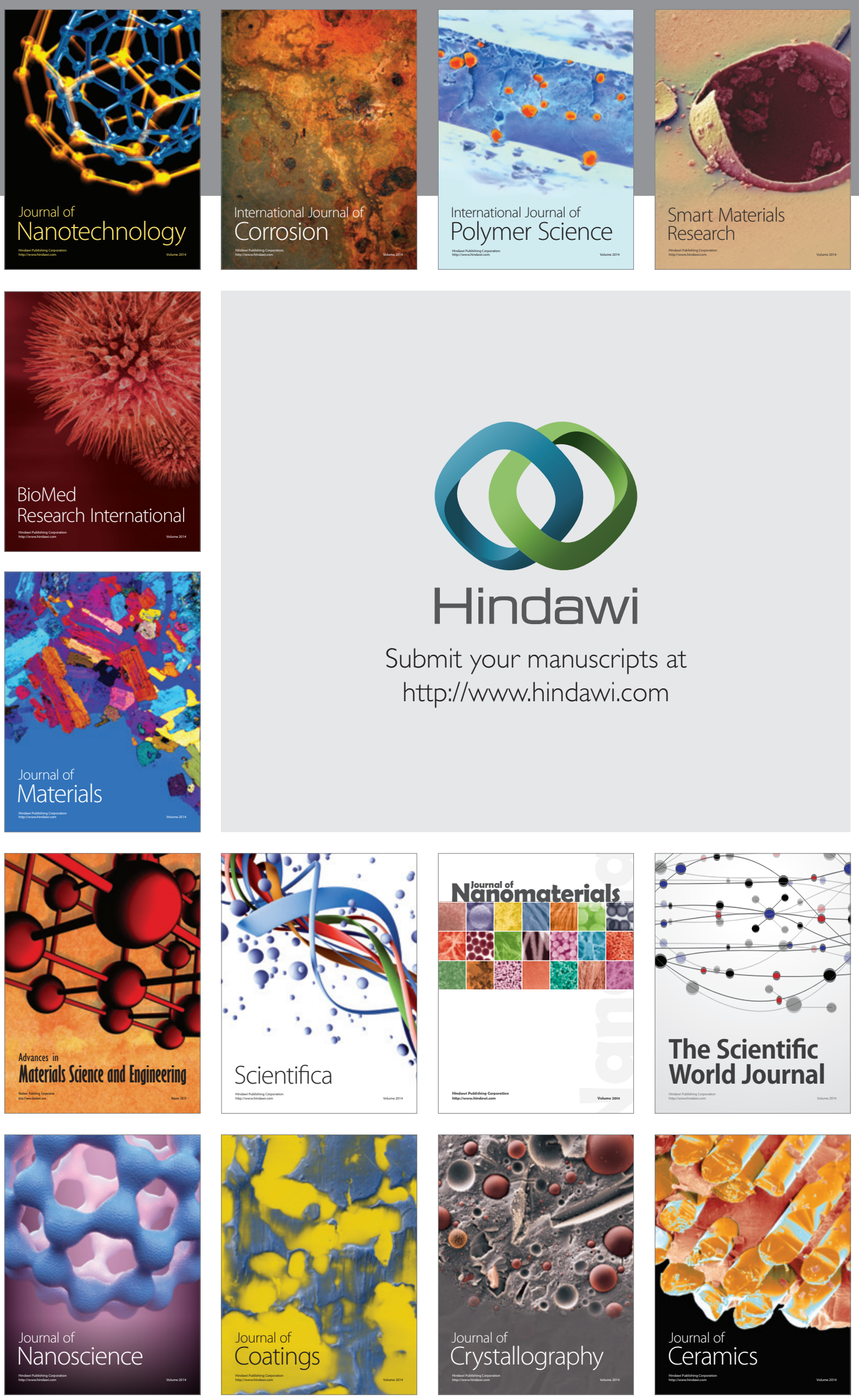

The Scientific World Journal

Submit your manuscripts at

http://www.hindawi.com

\section{World Journal}

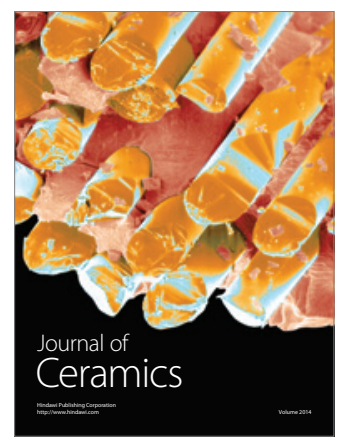

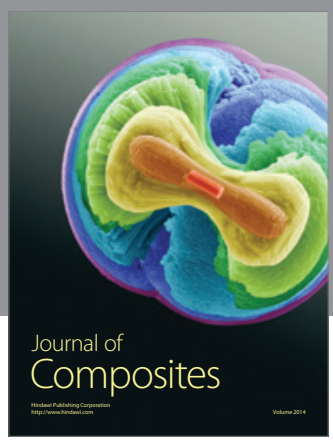
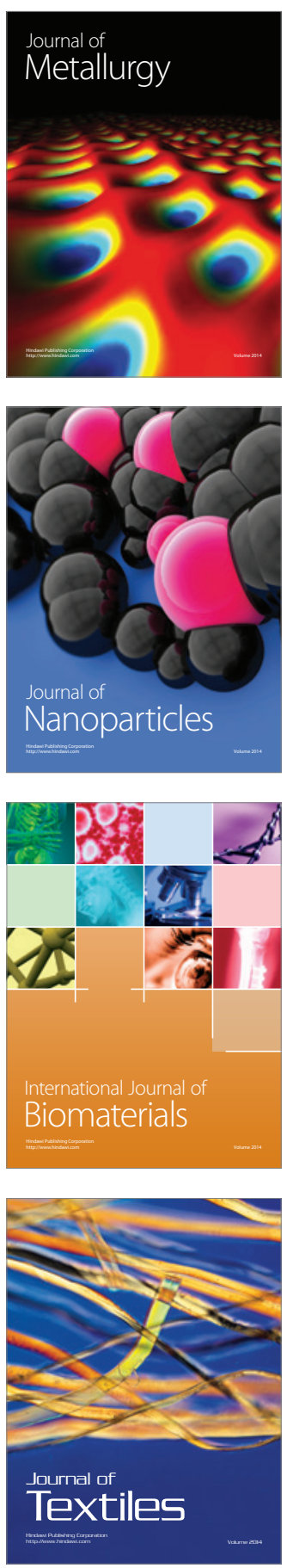